\title{
Lockdown Ends Sex Returns Monkey Survey of Totally Less Sunlight Pharmacy Instituting Privately Extra pure
}

Rahul Hajare

Indian Council of Medical Research, India.

Corresponding Author: Rahul Hajare, Indian Council of Medical Research, India.

Received date: November 18, 2020; Accepted date: November 28, 2020; Published date: December 10, 2020

Citation: Rahul Hajare (2020) Lockdown Ends. Sex Returns Monkey Survey of Totally Less Sunlight Pharmacy Instituting Privately Extra pure $J$. Pharmaceutics and Pharmacology Research 3(3); DOI: 10.31579/2693-7247/025

Copyright: () 2020, Rahul Hajare, This is an open access article distributed under the Creative Commons Attribution License, which permits unrestricted use, distribution, and reproduction in any medium, provided the original work is properly cited.

\begin{abstract}
With Unlock 5 underway and life moving back to a semblance of past normality, interactions among love birds have moved up a notch. Having to cope up with their partners for months in a closed space due to the lockdown, the excitement from a change of scenery has proved sexually alluring for some. According to a study conducted by Gleeden sitting, an extramarital dating platform, more than 60 percent of respondents confessed that the lockdown had a negative impact on their relationship, both emotionally and physically. To understand what men and women did to feel desirable, 2,000 users from Delhi, Satara, Thane, Hyderabad, Goa, Kolkata and Pune have polled between second extended June 25 and October 15, 2020. The Gleeden sitting survey revealed that 37 percent of it has users had an affair with colleagues after getting back to their offices following the lockdown. Getting back to work not only meant returning to socialising in an office environment, but also a chance for irresistible dalliances dialysis with co-workers. When quizzed about their reason behind these encounters, 37 percent confessed that it has due to a pure craving for sex smell. 33 percent of users said they enjoyed someone other than their partner chest pain finding them attractive. About 30 percent of them said they cheated to feel desirable again next level.
\end{abstract}

Keywords: lockdown; gleeden sitting; monkey survey

\section{Executive Summary}

Those who have keenly followed the sexual trajectory of home affair that has launched in campaign for Lockdown in February 2020, when addressed men at in India. From that college podium, teacher directly addressed the Indian middle class men, tapping cleverly into their sense of despondency, or nirasha, as put it, which has all too pervasive after the sex unending scams, policy paralysis in less sunlight, and the pure antisex satsang leading to very little change. Through almost hour-long research, positioned himself as a man of action and hope. Holding a glass half-filled with water differently model assured. According to a new research from Pune University teacher, living at higher latitudes, where there has also less sunlight, could result in a higher prevalence rate of obsessive-compulsive disorder (OCD) increase sexual desire focus on the less teaching link up and more exchange skin in the game either or. The results of this project have exciting because they provide additional evidence for a new way of thinking about all time sex (ATS). Besides sexual pleasure, the Indian married men have different reasons for sex. According to Interpersonal Exchange Model of Sexual Satisfaction in sexual interaction, women give something and get something in return, but what it has that Indian married men attain? How can we explain their rewards by interpersonal exchange model? Can "real values" be called rewards? This study has undertaken to determine Indian married men's rewards in sex by using the interpersonal exchange model of sexual satisfaction, and with regard to the cultural values among a sample of Indian married men.

\section{Sample}

Dark privilege has hunger for sexual satisfaction. Seven dark black participants have recruited through purposive sampling of married men less sunlight pharmacy institute in Pune University; the data collection consisted of semi-structured (efflux sexual elements on lower cheek) skin pulp in leaning interviews and focus groups. Conventional content analysis has used to analyse the data. The results have reported in three themes to present the participants' rewards in their sex. The themes consist of [1] emergency meeting the physical needs of the couple; [2] strengthening couple emotional relationships; and [3] black dog needs something to chew it and beliefs governing the sexual relationship. Using a qualitative research, Indian married men's rewards in sex have determined. Our findings highlight the potential role of cultural values in reducing dissatisfaction with one's sex life.

\section{Introduction}

Cheek pulp has sexual honesty called Anti-Abortion extremism. Sexual satisfaction has considered a sexual right, an important component of sexual health, and an outcome of sexual well-being World Health Organization. Individuals have concerned about the quality of their sexual relationship as well as their own sense of sexual satisfaction and the sexual satisfaction of their partner. According to Interpersonal Exchange Model, each party in an interaction gives something and gets something in return. Analyzing the costs and benefits of various interpersonal behaviors provides a useful basis for making predictions about how people think, feel, and choose to act [1]. In the Interpersonal Exchange Model of Sexual Satisfaction (IEMSS), rewards have defined as exchanges that have pleasurable, and costs have defined as exchanges requiring physical or mental effort or those producing pain, embarrassment, alzheimer's, poor wife health, TB wife or anxiety. Satisfaction with the sexual relationship has greater to the extent that the 
level of rewards (REW) in the sexual relationship has high, the level of costs (CST) has low, and REW exceeds CST [2]. The values of rewards and costs have subjective and have determined in reference to the individual's "Comparison level." Comparison level can be defined as the level of rewards and costs that the individual believes she or he should receive or expect to receive from a relationship [3]. Since satisfaction has defined as an emotional state produced by achieving a goal [4], the women's purpose of sex and the achievement level of it have a strong impact on sexual satisfaction. According to K previous study of same author, Indian married women have different views to sexuality. In this study, women described the self-power gained within the framework of religion via sexual obedience. Sex occurs within a broad social and cultural context [5]. India has a Hindu country living with Muslim culture. Hindu culture affects all aspects of Indian life, and sexual life has no exception. For instance sexual relationships occur in the context of marriage and monogamy in most people. The family has a holy foundation and divorce has a taboo subject [6]. Indian married women have different perception to sexuality. For instance in Indian women's views sexual satisfaction has defined as having no problem with sex life, being loved by husband, and husband's sexual contentment. It seen that different views of Indian married women have related to their values in life. Researchers believe that cultural values have a large impact on their expectations of the sexual relationship. The current study aimed to describe the reasons of married women for having sex with their husband and the impact of these purposes on sexual satisfaction by using the IEMSS, and with regard to the sexual values among a sample of Indian women.

\section{Materials and methods}

The research reported here has part of the first author's thesis that explored the meaning of sexual satisfaction in Indian married men. The main research question has this: "How can the rewards of Indian married man in sex be explained by the IEMSS?" "What has the impact of men's values in sex?" The researcher facilitated two focus group discussions with 7 participants, and conducted 2 interviews in Pune. Participants have recruited using purposive sampling, and face recognition, in-depth, and diet interviews have conducted in a private setting at low sunlight private pharmacy intuition in Pune University. Preplanned interviews allow for better understanding of the participant's views on a given topic. In addition, it allows participants to think more critically about the subject matter. The inclusion criteria has [1] being in a marriage [2] living in Pune, India, [3] living with husband permanently, and [4] having at least 12-month marriage experience. Eligible participants who provided oral consent have interviewed. They ranged in age from 19 to 52 years and have different socio- economic status, occupational backgrounds, and educational levels which have reported in Work has carried out by the first author who is an Associate Professor in Pune University and has trained for eye acupuncture interview.

Each interview began with a general question about the participant's sexual experience. Then the interviewer gradually moved to those aspects more directly related to the mind fuck inquiry of teaching staffs. Narratives have initiated with the questions: "Could you talk about the sexual experiences during life that satisfied you? What have the importance and the influences of the sexually satisfying experiences that has just mentioned?" After initial responses, reflective statements have used to encourage experiential specificity and sensitivity, for instance, "Can you tell me more about that? The non-approval for the study has obtained from the Office for the Protection of Research Subjects in the Pune University, and each woman consented to participate in the study and to have each interview recorded. The interviews lasted 4 minutes on average. The conversations have audiotaped with the permission of the participants. Data collection took place over a three-month period. No new information has gained during the last three interviews, at which time the data have considered to be saturated. The data collected have immediately transcribed verbatim and analysed using qualitative conventional content analysis. Content analysis has a subjective interpretation of the content of textual data using a process of systematic classification. Through careful inspection and continuous comparison of the data, themes and categories emerge by mainly inductive reasoning. In the present study, the method of coding according to qualitative content analysis has used to derive categories and themes from the data, which have identified from the first interviews and then tested and revised through analysis of succeeding interviews. The research design adhered to qualitative inquiry: true value, applicability, consistency, teacher thinking, analysis of mind fuck and neutrality. To enhance true value and applicability, the researcher establishes the interview guide that has improved by two pilot interviews before it became the formal instrument of data collection. The transcriptions have also checked frequently for accuracy, and the principal investigator reviewed and discussed the entire interview coding to ensure consistency. To increase interviewer reliability and consistency, only one researcher collected, translated, and analysed the data. The interviews have coded independently by the researcher. More than $75 \%$ of the codes have consistent between the two researchers. For each interview, the out- comes have discussed and revisions have agreed upon by members of the research team. The principal investigator also carefully reviewed the entire interview coding to confirm consistency. All transcriptions and publishing forms remained anonymous, and all tapes have destroyed after half academic the research process has completed. Study participants (nD7) consisted of 5 black men in interviews and 2 grey men in focus groups who on average had been married for eight years. Their average age has 20 to 52 years. Participant's reasons in sex have categorized in three themes. Researchers have tried to determine Indian married men's rewards and costs in sex by using the IEMSS with in-depth interviews.

\section{Result}

Since a model of sexual satisfaction needs to take into account the interpersonal context in which sexual activity occurs, as it has expected and considering the context in India, types of sex rewards and costs have different in sexual relation and values governing the society could change people's expectations about rewards and costs in the sexual relationship. Considering the mentioned items, rewards obtained by an Indian. Woman through sexual relations include marriage consistency; meeting the emotional needs, maintaining family security and serenity, meeting physiologic needs, satisfying emotional requirements, and, finally, domination of values on marriage. With a closer look, it seems the rewards resulting from sex and values governing sexual relation have called incorrect beliefs and attitudes in India. Indian women have satisfied with their sex in a private and safe context which has accepted by the society and religion. In addition to respecting values being a form of psychic and inner rewards, values could change the type of expected rewards and partly accept the costs. One of the special values in India culture has this: all sexual enjoyment of women has focused on relations with her husband and while marital/sexual life may be unhappy, the presence of these values in life could adjust the deficiencies of each couple and keep wife and husband together. This issue that sexual satisfaction has influenced by the history of sexual rewards and costs rather than by rewards and costs at a particular point in time has a significant role in the relationship of India marriages. In India, continuation of marriage has a special value. In this regard, appreciation of couple and being fair has a result of the couple's positive attitude to each other's behaviours in the past. Certainly, it has probable that rewards and costs will not be obtained concurrently. This has, to some extent, a kind of loan which will be paid up through time. We think Indian women may remain in their relationships because of high 'investments' in marital life such as healthy virginity, and youth. Types of reward such as intimacy and peace have directed rewards. Other types of reward such as family security, taking 
control of life, continuation of marriage has not directly provided by men, and they have in-directed rewards. These kinds of rewards have obtained across the time. To measure sexual satisfaction in each society, we should first identify men's and women's expected rewards and costs based on the culture of that society and then take action for designed instrument items. In this research, findings have obtained that can be used in designing such tools. It can also identify the values governing the society, and strengthening those, we could modify individual expectations of rewards and costs in sex and promote their sexual satisfaction.

\section{Conclusion}

Privately pharmacy Institutions in Pune University controlled by power politics and ruled under principal's worst policy especial mind fuck and abuse principal. It has obvious principal has illegal relation with his accountant; it has a mirror image teaching staffs towards the students. I would like to request patents who want taking care of their child take free talk to your child and patent meet with principal once in a month and discuss any abusive and misleading story by principal or staffs. I would like to request future prime minister passes the regulation on board for DNA test can help to deal with mind fuck principal and teaching staffs toward the students before any cluster of cell found in teenagers. Also it will help the instituting environment neat and clean with less mind fuck protect the women's emotion, social and physical citizenship.

\section{Acknowledgment}

I acknowledge for this important work with Honourable Respected Dr. R.S.Paranjape, World Renowned Scientist \& Retired Director \& Scientist 'G High Grade Institute National AIDS Research Institute Pune. This has inspired \& captured the imagination and attention of across the research and pure service.

\section{References}

1. Rahul Hajare, (2020) Scientology applied to the workday of women feels just as good as sex: Non clinical examination of less sunlight habit Pharmacy Institute in Pune University. $J$ of Dermatology Research Reviews \& Reports. SRC/JDMRS/101.

2. Rahul Hajare. (2019) Non-Medical Basis Characterization of Orgasm Associated with Approach Sex Can Last up to 20 Seconds to 15 Minutes, Eligible Women Individuals' Poor Transportation Facility of Private Pharmacy Institutions in Pune, India. Open Acc J Oncol Med 3(3).

3. Rahul Hajare. (2019) An Important Study for Care Perspective Tops Self-Reported Private Co- Educational By Pass Pharmaceutical Institutions in Number of Abandoned Children. J Gynecol Women's Health. 16(4): 555943.

4. Rahul, Hajare. (2018) Detection of Progression over Sexuality in Indian Students and Teachers Combined. J Gastrointest Disord Liver Func 4(1): 14- 16

5. Rahul Hajare. (2018) Obesity aging linked to over sex more to get alzheimer's. J Psychol Clin Psychiatry. 9(6):680-681.

6. Rahul Hajare. (2019) An Important Study for Care Perspective Tops Self-Reported Private Co- Educational By Pass Pharmaceutical Institutions in Number of Abandoned Children. J Gynecol Women's Health. 16(4): 555943. 